OPEN ACCESS

Edited by:

Shangfeng Chen,

Institute of Atmospheric Physics,

Chinese Academy of Sciences

(CAS), China

Reviewed by:

Ruowen Yang,

Yunnan University, China

Chujie Gao,

Hohai University, China

*Correspondence:

Xiaojuan Wang

mouse0903@126.com

Specialty section:

This article was submitted to Climate Services,

a section of the journal

Frontiers in Climate

Received: 13 April 2021

Accepted: 28 July 2021

Published: 29 September 2021

Citation:

Shen H, Gong Z, Liu B, Guo Y, Feng $X$, Wen $T$, Wang $X$ and Feng $G$ (2021) Remote Effects of IOD and

ENSO on Motivating the Atmospheric Pattern Favorable for Snowfall Over the Tibetan Plateau in Early Winter.

Front. Clim. 3:694384.

doi: 10.3389/fclim.2021.694384

\section{Remote Effects of IOD and ENSO on Motivating the Atmospheric Pattern Favorable for Snowfall Over the Tibetan Plateau in Early Winter}

\author{
Hongyan Shen ${ }^{1,2,3}$, Zhiqiang Gong ${ }^{3,4}$, Boqi Liu ${ }^{5}$, Yipeng Guo ${ }^{6}$, Xiaoli Feng ${ }^{2}$, Tingting Wen ${ }^{2}$, \\ Xiaojuan Wang ${ }^{3 *}$ and Guolin Feng ${ }^{1,4,7}$ \\ ${ }^{1}$ College of Atmospheric Sciences, Lanzhou University, Lanzhou, China, ${ }^{2}$ Qinghai Climate Center, Qinghai Meteorological \\ Administration, Xining, China, ${ }^{3}$ College of Physics and Electronic Engineering, Changshu Institute of Technology, Suzhou, \\ China, ${ }^{4}$ National Climate Center, China Meteorological Administration, Beijing, China, ${ }^{5}$ State Key Laboratory of Severe \\ Weather and Institute of Climate System, Chinese Academy of Meteorological Sciences, Beijing, China, ${ }^{6}$ College of \\ Atmospheric Sciences, Nanjing University, Nanjing, China, ${ }^{7}$ Southern Marine Science and Engineering Guangdong \\ Laboratory, Zhuhai, China
}

The interannual variation of snowfall over the Tibetan Plateau (TP) in early winter (November-December) and its related atmospheric attribution are clarified. Meanwhile, the influence of tropical sea surface temperatures (SSTs) on TP snowfall is investigated by diagnostic analyses and Community Atmosphere Model (CAM5) simulations. The leading mode of TP snowfall in early winter features a spatially uniform pattern with remarkable interannual variability. It is found that the Indian Ocean Dipole (IOD) and El Niño Southern Oscillation (ENSO) are main external forcing factors for TP snowfall. Positive IOD with positive ENSO and positive IOD with neutral ENSO cases both have remote impact on motivating Southern Eurasia (SEA) pattern, which can induce an anomalous cyclone around the TP. The corresponding anomalous ascending motion and cold air in the mid-upper troposphere provide the dynamical and thermal conditions for heavy snowfall. The low-level southwesterly winds are enhanced over the Arabian Sea and Bay of Bengal, bringing abundant water vapor into the TP for excessive snowfall. Furthermore, CAM5 simulation experiments forced by IOD- and ENSO-related SST anomalies are performed to verify their combined and independent effects on TP snowfall in early winter. It is confirmed that either positive IOD or El Niño has certain impacts on motivating circulation anomalies favorable for snowfall over the TP. However, IOD plays a leading role in producing the excessive snowfall-related atmospheric conditions, and there is an asymmetric influence of ENSO and IOD on the TP snowfall.

Keywords: snowfall, Indian Ocean Dipole, El Niño-Southern Oscillation, remote effects, early winter

\section{INTRODUCTION}

Although winter precipitation accounts for a relatively small fraction of total annual rainfall comparing to summer season, it experiences obvious annual variability over some regions such as the Tibetan Plateau (TP). Snowfall is solid precipitation formed by condensation of moisture in the air. Heavy snowfall may be a natural hazard to life and property. Severe cold surges accompanied with heavy snowfall during winter can significantly impact agriculture, transportation, livestock 
production, and water resources, resulting in serious economic losses. In the context of climate warming, intense snowfall has hit China more frequently in recent winters and caused severe damages to the sustainability of the society. For instance, a severe snowfall event that occurred in later winter 2008 over southern China led to an economic loss of above 20 billion US dollars and affected more than 100 million people (Zhou et al., 2009, 2011).

The Tibetan Plateau (TP), known as the third pole and Asia's water tower, frequently suffers from severe snowfall events due to the combined effects of its steep topography, the East Asian winter monsoon (Webster, 1998; Wu et al., 2011, 2012), and the westerly circulation (Schieman et al., 2009). Entering early winter, the TP ground becomes frozen, and snow is the main form of precipitation over the TP. Snowfall is an important element of the hydrological cycle, replenishing soil moisture, and contributing runoff to river basins through spring melt (Lettenmaier and Gan, 1990; Groisman et al., 2001). Therefore, understanding the mechanism of TP snowfall can provide insights on better prediction of winter climate.

The El Niño-Southern Oscillation (ENSO), which is the strongest atmosphere-ocean coupled mode on the interannual scale, is one of the most important factors that can influence winter climate variability in Eurasia (Wang et al., 2000; Sun and Wang, 2010; Zhou and Wu, 2010; Jia and Lin, 2011; Wang and Feng, 2011; Gong et al., 2014, 2017; Wang and Chen, 2014; Ge et al., 2016). Yang (1996) found that the Eurasian winter snow cover increased during El Niño winters (and decreased during La Niña winters). Using a global atmospheric general circulation model (GCM), Meehl (1997) proposed a hypothesis that the tropical sea surface temperature (SST) has crucial impact on the south Asian monsoon, which can further affect the midlatitude snow, especially over the Eurasia. Dong and Valdes (1998) also found evidence that El Niño conditions lead to increased snow in Eurasia. Wang and Chen (2010) point out that the western Pacific subtropical high can act as a bridge for ENSO's influence on the East Asian climate. During El Niño events, this system can enhance the moisture transport to China and cause abnormally wet conditions. El Niño might excite the stationary Rossby waves extending along the North AfricanAsian jet, resulting in anomalous increase of potential vorticity and snow depth over the TP in winter, based on the Nimbus-7 Scanning Multichannel Microwave Radiometer (SMMR) satellite estimates of snow depth (Shaman and Tziperman, 2005). This mechanism was confirmed by Wang and Xu (2018), who used snow water equivalent data from 1987 to 2007.

On the other hand, based on satellite data, Yuan et al. (2009, 2014) reported that the interannual variability of the winter TP snow cover is linked to Indian Ocean dipole (IOD) rather than ENSO, and emphasized that in the pure ENSO years with no co-occurrences of IOD, the influence of ENSO on TP snow cover is negligible (Yuan et al., 2009). Using the ERA-Interim reanalysis data, Zhang et al. (2019) also found the IOD forcing on snow depth over the TP. Jiang et al. $(2013,2019)$ claimed that anomalous convection over the western Indian Ocean related to the positive IOD could generate a wave train propagating northeastward and induce an anomalous cyclonic circulation over the central western TP, then transport extra moisture from the tropics to the central western TP, causing deep snow depth there. The above studies concentrated on TP snow cover/depth affected by IOD or ENSO through the low-latitude circulations, but less has been investigated in the mid- and high-latitude circulation pattern.

In addition, it is interesting why these studies have obtained different conclusions regarding the impacts of ENSO and IOD on snow over the TP. It is confusing whether the ENSO can affect snow over the TP or not. Of note is that two satellite-based or reanalysis-based snow parameters have been investigated in these studies: snow cover and snow depth (Shaman and Tziperman, 2005; Yuan et al., 2009, 2014; Wang and $\mathrm{Xu}, 2018$; Zhang et al., 2019). The snow depth derived from satellites shows considerable biases (Frei et al., 2012). Thus, it is necessary to use in situ snowfall data to reinvestigate the relationship of TP snowfall with ENSO and IOD. Direct observations of snowfall in situ have a certain length of record and spatial coverage. They are issued after strict quality control, which can promote the study reliability about TP snow. On the other hand, snowfall is the major precipitation event over the TP in winter. Heavy snowfall and freezing temperature lead to snow cover/depth on the ground for a long time. Therefore, snowfall is the leading and direct factor that produces and maintains snow cover/depth. As a result, the changes in TP snowfall have yet to be systematically addressed, and what processes decides the severe TP snowfall is still not fully understood. Given the serious impacts of snowfall events, investigating the possible causes in snowfall is an urgent necessity for disaster prevention and mitigation. Furthermore, most previous studies investigating the contributions of ENSO and/or IOD to the precipitation variation over China only considered a single index for ENSO or IOD. Results obtained without considering the interdependence of ENSO and IOD might include the impacts of both factors. Since ENSO and IOD sometimes co-occur, it is also necessary to identify their respective and combined influences on TP snowfall. Moreover, it is important to explore the influences of IOD and ENSO on the snowfall over TP in early winter utilizing the statistic and simulation approaches.

This paper examines the interannual variability of the early winter snowfall over the TP and the underlying physical mechanisms, especially focusing on independent and joint roles of IOD and ENSO on influencing the TP early winter snowfall. The paper is organized as follows. Section Data, Method, and Model introduces the data and methodology. Section Spatial-Temporal Features of TP Early Winter Snowfall presents the characteristics of snowfall over the TP in early winter. Section SSTAs Associated With Early Winter TP Snowfall discusses the SSTAs associated with early winter snowfall over the TP. Section Numerical Experiments analyzes IOD and ENSO associated with TP early winter snowfall by statistics, and then validates the observed and statistical results utilizing the Community Atmosphere Model version 5 (CAM5) model. Section Conclusion and Discussion provides a brief conclusion and discussion of this study. 


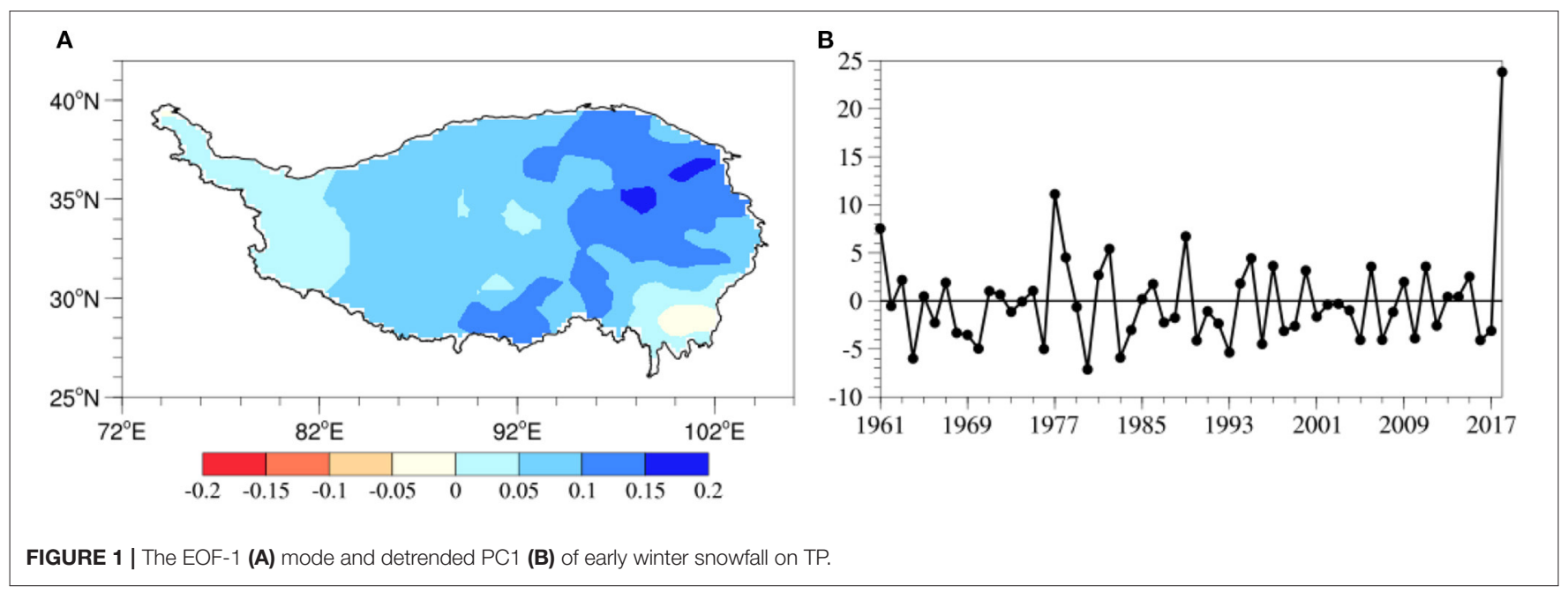

\section{DATA, METHOD, AND MODEL}

In this paper, snowfall data are collected from 85 observation stations over the TP, which are released by the National Meteorological Information Center of China Meteorological Administration. These stations are located in Qinghai (45 stations), Xizang (19 stations), Gansu (4 stations), and Sichuan (17 stations) Provinces, respectively. The monthly snowfall during early winter (November-December) was derived from the daily observation records during 1961-2018. The largescale atmospheric state is obtained from the NCEP/NCAR reanalysis data (Kalney et al., 1996). The variables include geopotential height, horizontal wind, humidity, and vertical velocity, with a horizontal resolution of $2.5^{\circ} \times 2.5^{\circ}$. Monthly mean sea surface temperature (SST) data were based on the Extended Reconstruction SST version 5 (ERSST5) dataset, which is provided by the NOAA/Oceanic and Atmospheric Research (OAR)/Earth System Research Laboratory of Physical Science (Huang and Cai, 2017). The period of the dataset is from 1961 to 2018, and early winter in this article refers to November-December.

A wave-activity flux (WAF) derived by Takaya and Nakamura (2001) is used to diagnose the mid-high-latitude wave train (Equation 1).

$W=\frac{p \cos \varphi}{2|\vec{U}|}\left\{\begin{array}{l}\frac{U}{a^{2} \cos ^{2} \varphi}\left[\left(\left(\frac{\partial \psi}{\partial \lambda}\right)^{2}-\psi \frac{\partial^{2} \psi}{\partial \lambda^{2}}\right)\right]+\frac{V}{a^{2} \cos \varphi}\left[\frac{\partial \psi}{\partial \lambda} \frac{\partial \psi}{\partial \varphi}-\psi \frac{\partial^{2} \psi}{\partial \lambda \partial \varphi}\right] \\ \frac{U}{a^{2} \cos \varphi}\left[\frac{\partial \psi}{\partial \lambda} \frac{\partial \psi}{\partial \varphi}-\psi \frac{\partial^{2} \psi}{\partial \lambda \partial \varphi}\right]+\frac{V}{a^{2}}\left[\left(\frac{\partial \psi}{\partial \varphi}\right)^{2}-\psi \frac{\partial^{2} \psi}{\partial \varphi^{2}}\right] \\ \frac{f_{0}^{2}}{N^{2}}\left[\frac{U}{a \cos \varphi}\left(\frac{\partial \psi}{\partial \lambda} \frac{\partial \psi}{\partial z}-\psi \frac{\partial^{2} \psi}{\partial \lambda \partial z}\right)+\frac{V}{a}\left(\frac{\partial \psi}{\partial \varphi} \frac{\partial \psi}{\partial z}-\psi \frac{\partial^{2} \psi}{\partial \varphi \partial z}\right)\right]\end{array}\right\}$

In which $(U, V)$ are the climatological winds in the zonal and meridional directions; $(\lambda, \varphi)$ are longitude and latitude, $a$ is the earth's radius; $z=-H \ln p ; p=$ pressure $/ 1000 \mathrm{hPa} ; H$ is the constant scale height; $\psi$ is the perturbation of geostrophic stream function; $|\vec{U}|$ is the magnitude of the wind; $f_{0}$ is the Coriolis parameter; and $N^{2}$ is the buoyancy frequency.
The moisture flux $(\vec{Q})$ and its divergence $(\vec{D})$ are calculated as:

$\vec{Q}=-\frac{1}{g} \int_{p_{u}}^{p_{s}} q \vec{V} d p, Q_{\lambda}=-\frac{1}{g} \int_{p_{u}}^{p_{s}} q u d p, Q_{\varphi}=-\frac{1}{g} \int_{p_{u}}^{p_{s}} q v d p$

$$
\vec{D}=-\nabla \cdot \vec{Q}=-\frac{1}{a \cos \varphi}\left(\frac{\partial Q_{\lambda}}{\partial \lambda}+\frac{\partial Q_{\varphi} \cos \varphi}{\partial \varphi}\right),
$$

where $p_{s}$ is the surface pressure; $p_{u}$ is the pressure of the top moisture layer ( $300 \mathrm{hPa}$ ); $p$ is pressure; $q$ is the specific humidity; and $(u, v)$ are horizontal velocity components. $a$ is earth radius, $\lambda$ is longitude, $\varphi$ is latitude.

The present study also used the statistical analysis to show the features and circulation associated with the early winter snowfall over the TP, including the empirical orthogonal function (EOF) analysis, correlation and partial correlation analysis, and composite analysis methods.

The Community Atmosphere Model version 5 (CAM5) model is utilized for validating the observed and statistical results. As stated in the introduction, it is derived from the model used in Khairoutdinov and Randall (2001) and is a component of Community Earth System Model developed at NCAR with many external collaborators. This model uses a default finite-volume dynamical core with a hybrid pressuresigma vertical coordinate (Simmons and Burridge, 1981) that has 30 levels with a top at $2.255 \mathrm{hPa}$. The CAM5 has the same land, ocean, and sea ice components as in CCSM4, with the biggest change occurring in the atmosphere. The CAM5 is essentially new atmospheric model with improved and more realistic formulations of radiation, boundary layer, and aerosols. CAM5 features (1) a new shallow convection scheme and a new moist turbulence scheme developed by the University of Washington, (2) a two-moment cloud microphysics scheme, and a cloud macrophysics scheme from the parameterizations of clouds. 
The model code can be downloaded from the NCAR code repository online and was run locally at the National Meteorological Information Center (NMIC) of the China Metrological Administration (CMA). This model has been widely used to investigate the effects of the underlying condition on the winter climate. Four sets of numerical experiments are designed with CAM5 driven by the global SST data of Hadley Center. One is a control experiment forced by the global SST climatology of observational monthly SST data in early winter, and the other three are sensitivity experiments forced by combined IOD and ENSO, independent IOD with no co-occurrence of El Niño, and independent El Niño with no co-occurrence of IOD. The first principal component (PC1) of TP snowfall in early winter by using the Empirical Orthogonal Function (EOF) expansion is defined as the TP snowfall index. We add the regression SST value against this index to the climatology as SST external forcing signal. The three sensitivity experiments represent the single IOD and ENSO forcing, respectively, and IOD-ENSO joint forcing. Each experiment includes 10 members with different initial states in order to verify the sensitivity to different atmospheric initial values, and the 10-member average results will be used for analysis. The differences between the sensitivity and control runs show the influences of SSTAs on the early winter snowfall over the TP.

\section{SPATIAL-TEMPORAL FEATURES OF TP EARLY WINTER SNOWFALL}

\section{Interannual Variation of TP Snowfall}

Interannual variability of the early winter snowfall over the TP is revealed by using the Empirical Orthogonal Function (EOF) expansion (Figure 1) based on solid precipitation observations over the TP from 85 stations. The first EOF mode (EOF1) explains about $32.2 \%$ of the total variance and exhibits a regional consistency of snowfall anomaly (Figure 1A). The higher loading value lies in the Northeast and center of TP, which is the frequent location of snow disaster. The corresponding first principal component (PC1) shows a remarkable interannual variability (Figure 1B). For example, in winter 2018, heavy snowfall occurred in the northeast of the Tibetan Plateau. Such an extreme snowfall is enhanced as a possible response to climate warming. Sun and Wang (2010) claimed that heavy snow events of more than $5 \mathrm{~mm}$ /day increased in the eastern of TP since the 1960s. At the same time, the snow days have increased (Zhou et al., 2017). Danco et al. (2016) used phase 5 of the Coupled Model Inter-comparison Project (CMIP5) to reveal that snow rate and heavy snowfall frequency will increase during 2021-2050 and 2070-2100 over the TP. Therefore, TP snow disaster may become a severe challenge in the future.

\section{Atmospheric Circulation}

Now we discuss the atmospheric circulation affecting the TP early winter snowfall. Firstly, simultaneous regressions of 200- and 500 -hPa geopotential height (GPH) against PC1 of TP snowfall in early winter show a wave train with barotropic structure
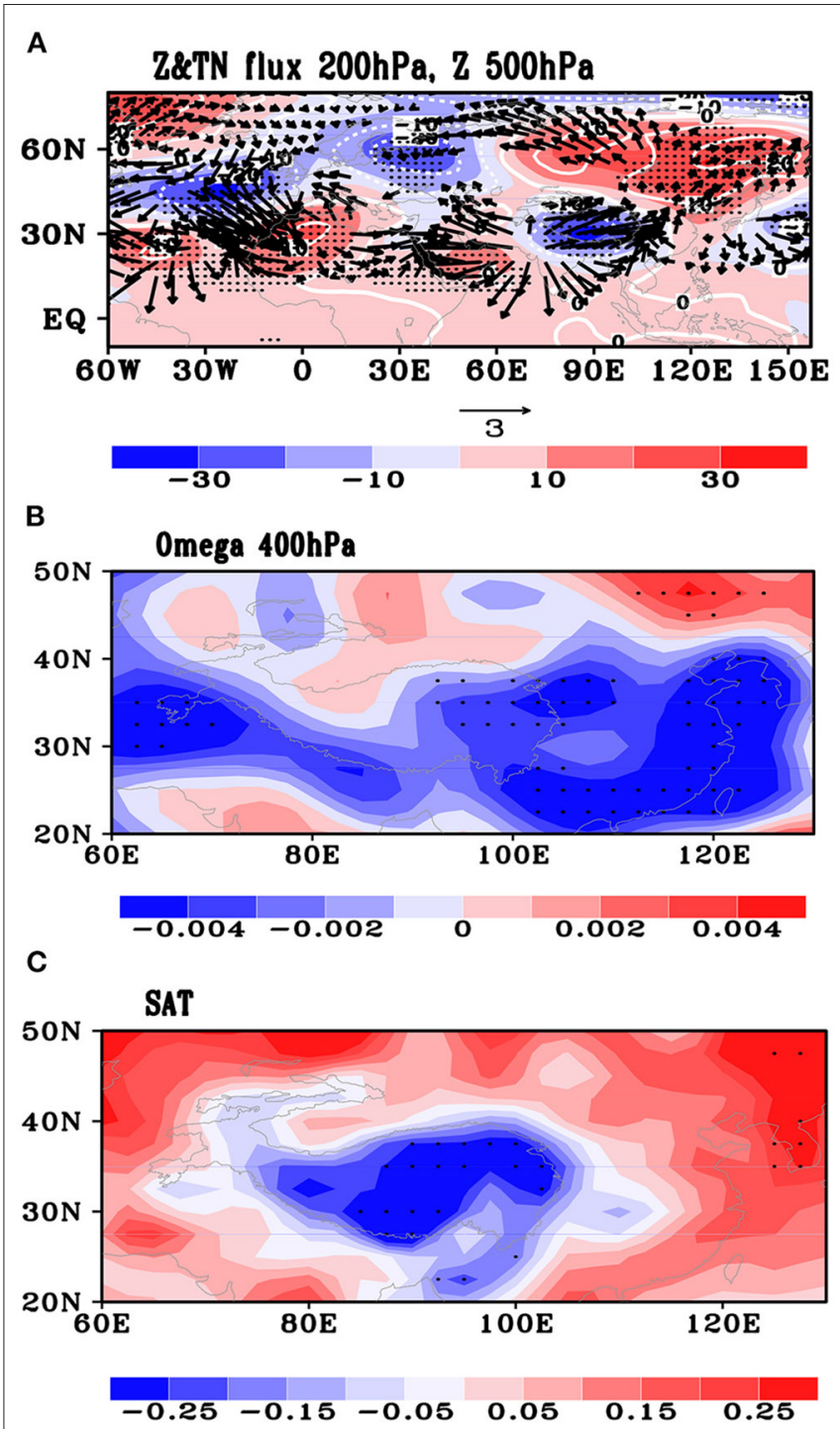

D

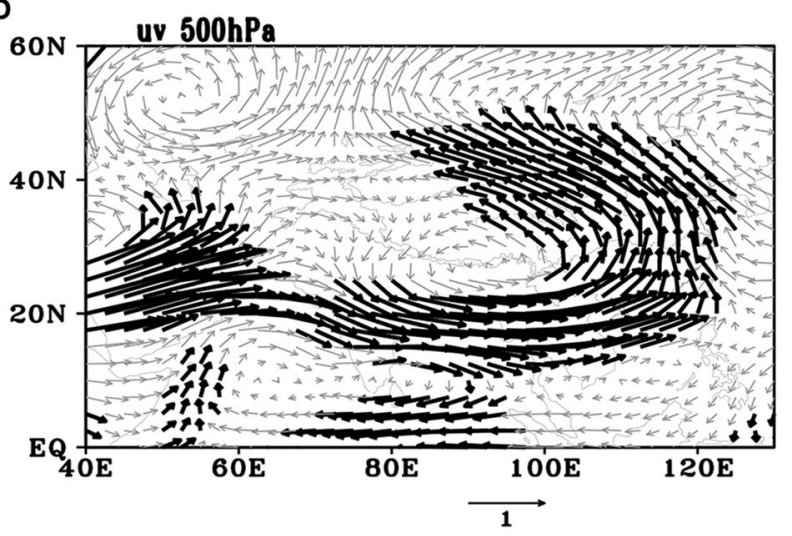

FIGURE 2 | (A) 200-hPa Geopotential height (shadings, gpm) and wave activity fluxes (vectors, $\mathrm{m}^{2} \mathrm{~s}^{-2}$ ) and 500-hPa geopotential height (contours, gpm), (B) $400 \mathrm{hPa}$ vertical velocity $\left(\mathrm{Pa} \mathrm{s}^{-1}\right)$ and (C) surface temperature $\left({ }^{\circ} \mathrm{C}\right)$, (D) 500-hPa horizontal wind $\left(\mathrm{m} \mathrm{s}^{-1}\right)$ regressed against PC1 of TP snowfall in early winter. Black dots in (A-C) and the bold vector in (D) indicate the values exceeding the $95 \%$ confidence level. 


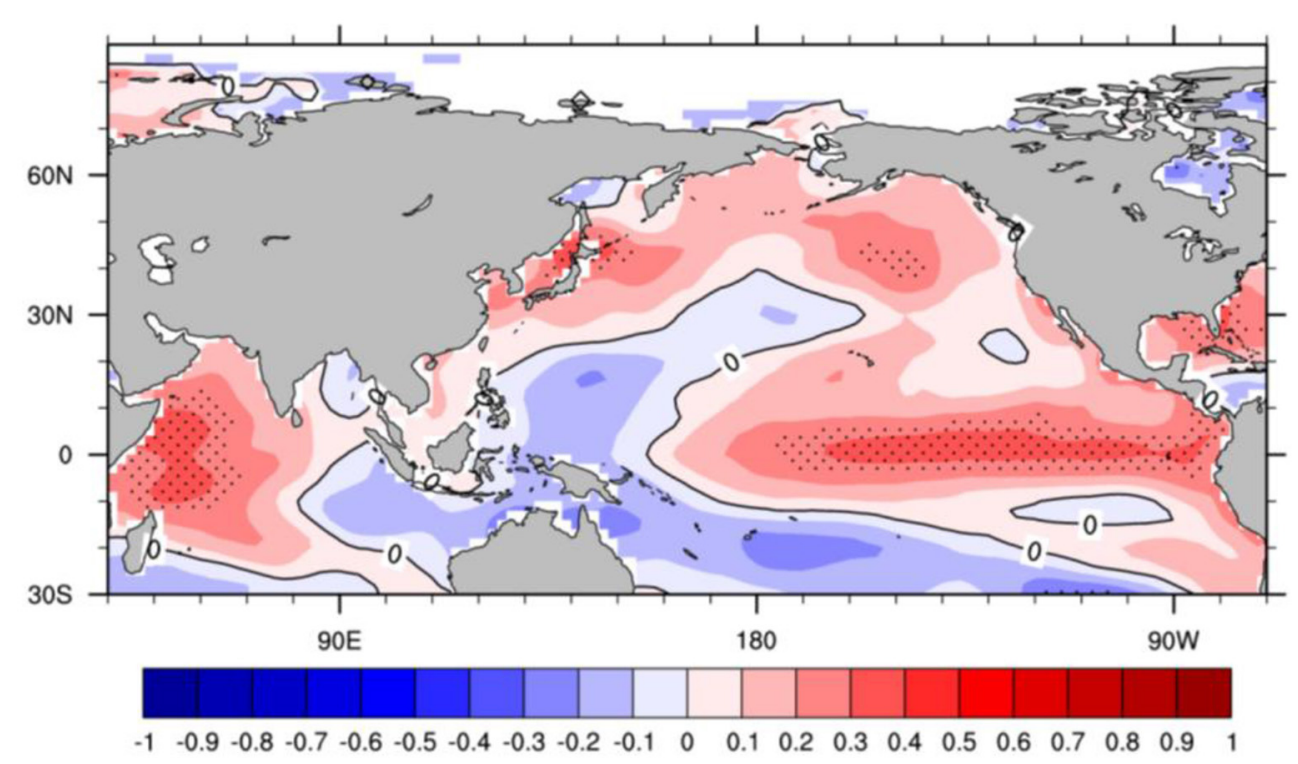

FIGURE 3 | Regression of global sea surface temperature (unit: ${ }^{\circ} \mathrm{C}$ ) in early winter against PC1 of TP snowfall in early winter (black dots indicate the values exceeding the $95 \%$ confidence level).

from Southwest Europe-Northwest Africa to East Asian at midhigh latitude (Figure 2A). The WAF suggests that the wave train originates from Greenland and then extends to Northeast Asia with two propagating pathways (Figure 2A). One is from Greenland to North Atlantic and Sahara as the North path, and the other one stems from the Arabian Peninsula and propagates northeastward to TP and Northeast Asia. We defined two indices to describe the two pathways of the wave train (Equation 4). The South index (SI) is based on averaged anomalous geopotential height at level $500 \mathrm{hPa}$ over the TP, Arabian Peninsula, and Northeast Asia as formula (4). The North index (NI) also includes three centers over Greenland, North Africa, and North Atlantic, respectively. These two indices properly reflect features of remote connections across the Eurasia continent, which can be used to identify whether the northern or southern wave train has more significant impact on the atmospheric circulations over the $\mathrm{TP}$ region.

$$
\begin{array}{r}
S I=H_{T P}\left(80-105^{\circ} E, 25-32^{\circ} N\right)-H_{A P}\left(32-60^{\circ} E, 10\right. \\
\left.-20^{\circ} N\right)-H_{N E A}\left(100-140^{\circ} E, 45-60^{\circ} N\right) \\
N I=H_{G L}\left(58-32^{\circ} W, 60-70^{\circ} N\right)+H_{N A}\left(15 W-15^{\circ} E, 25\right. \\
\left.-40^{\circ} N\right)-H_{N A T}\left(50-20^{\circ} W, 40-50^{\circ} N\right)
\end{array}
$$

The SI and NI are two indices, respectively. The $H_{T P}$ is the Tibetan Plateau region $\left(100-140^{\circ} \mathrm{E}, 45-60^{\circ} \mathrm{N}\right)$ geopotential height departure; similarly, $H_{A P}$ refers to Arabian Peninsula (32$\left.60^{\circ} \mathrm{E}, 10-20^{\circ} \mathrm{N}\right), H_{N E A}$ Northeast Asian $\left(100-140^{\circ} \mathrm{E}, 45-60^{\circ} \mathrm{N}\right)$, $H_{G L}$ Greenland $\left(58-32^{\circ} \mathrm{W}, 60-70^{\circ} \mathrm{N}\right), H_{N A}$ North Atlantic (50$\left.20^{\circ} \mathrm{W}, 40-50^{\circ} \mathrm{N}\right)$, and $H_{N A T}$ North Atlantic $\left(50-20^{\circ} \mathrm{W}, 40-\right.$ $\left.50^{\circ} \mathrm{N}\right)$.
TABLE 1 | Temporal correlation coefficients (TCC) between PC1 and IOD/ENSO indices.

\begin{tabular}{lll}
\hline & IOD & ENSO \\
\hline Correlation & 0.50 & 0.31 \\
Partial correlation & 0.45 & 0.10
\end{tabular}

The SI and NI present significant negative correlation with -0.48 temporal correlation coefficient (TCC). The TCC between PC1 and SI (NI) is $-0.52(0.39)$, respectively. All the TCCs have exceeded the $99.9 \%$ confidence level. This results implicate more the important role of the southern path on early winter snowfall over TP. Actually, the southern path of this wave train is similar to the Southern Eurasian (SEA) teleconnection (Xu et al., 2012; $\mathrm{Li}, 2016$ ). It is one of the Eurasian (EU) patterns (Wallace and Gutzler, 1981). In boreal winter, the SEA teleconnection pattern is an important intermediate track linking the NAO and weather climate over East Asia (Xu et al., 2012; Li, 2016). Five main centers of action lie in the following regions: Southwest Europe, the Middle East, the Arabian Sea, the Tibetan Plateau/Southwest China, and Northeast Asia (Li et al., 2019).

In Figure 2A, the prominent positive geopotential height anomalies embedded in the wave train exist in the Southwest of Europe, Northwest of Africa, TP, and Northeast Asia. This anomalous center at $500 \mathrm{hPa}$ level is in agreement with the characteristic of the SEA pattern. The positive (negative) SEA pattern in boreal winter indicates positive (negative) geopotential height anomalies over Southwest Europe and the Arabian Sea, as well as Northeast Asia (the Middle East and Tibetan Plateau/Southwest China), and more (less) precipitation in 
TABLE 2 | Frequency (number of years) corresponding to IOD and ENSO combinations during 1961-2018.

\begin{tabular}{lcccc}
\hline & $\mathbf{I}^{+}$ & $\mathbf{I}^{\mathbf{0}}$ & $\mathbf{I}^{-}$ & Total \\
\hline $\mathrm{P}^{+}$ & 6 & 8 & 1 & 15 \\
$\mathrm{P}^{0}$ & 4 & 21 & 5 & 31 \\
$\mathrm{P}^{-}$ & 1 & 5 & 7 & 12 \\
Total & 11 & 35 & 12 & 58 \\
\hline
\end{tabular}

$I^{+}, P^{0}$, and $I^{-}$represent the strong positive (IOD index value higher than 0.7 standard deviations), neutral (IOD index value between -0.7 and 0.7 standard deviations), and negative (IOD index value lower than -0.7 standard deviations) cases, respectively. $P^{+}$, $P^{0}$, and $P^{-}$represent the same meaning but for ENSO index.

TABLE 3 | Years of IOD and ENSO combinations.

\begin{tabular}{lcccccc}
\hline Categories & $\mathbf{I}^{+} \mathbf{P}^{+}$ & $\mathbf{I}^{+} \mathbf{P}^{\mathbf{0}}$ & $\mathbf{P}^{+} \mathbf{I}^{\mathbf{0}}$ & $\mathbf{I}^{-} \mathbf{P}^{-}$ & $\mathbf{I}^{-} \mathbf{P}^{\mathbf{0}}$ & $\mathbf{P}^{-} \mathbf{I}^{\mathbf{0}}$ \\
\hline Frequency & 6 & 4 & 8 & 7 & 5 & 5 \\
Years & 1963 & 1961 & 1965 & 1974 & 1966 & 1983 \\
& 1972 & 1967 & 1969 & 1984 & 1971 & 1988 \\
& 1997 & 1977 & 1982 & 1998 & 1973 & 1995 \\
& 2006 & 2012 & 1986 & 2005 & 1993 & 1999 \\
& 2015 & & 1991 & 2007 & 1996 & 2011 \\
& 2018 & & 1994 & 2010 & & \\
& & 2002 & 2016 & &
\end{tabular}

The meaning of $I^{+}, I^{0}, I^{-}, P^{+}, P^{0}$, and $P^{-}$are the same as that in Table 2.

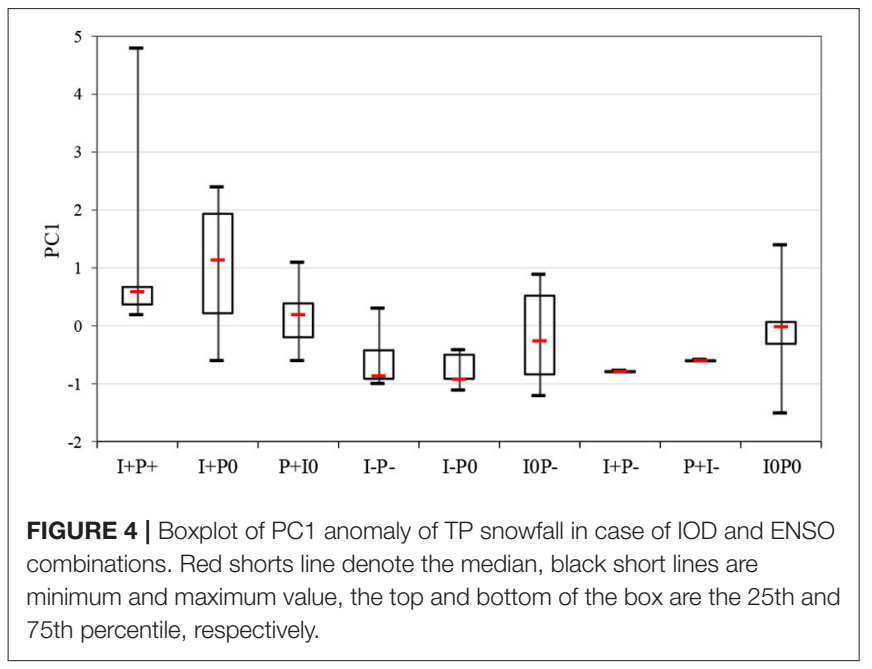

Southwest China (Li et al., 2019). Therefore, the SEA pattern may have a close connection to TP snowfall. The significant negative center is also observed at $200 \mathrm{hPa}$ over the TP. They accompany the $500 \mathrm{hPa}$ anticyclonic anomalies over the Arabian Sea at lower latitude and anomalous cyclone around the TP at mid-high latitude from North Africa to East Asia (Figure 2D). The southerly wind gets enhanced around the TP, which can transport more water vapor from the Bay of Bengal into the TP. In the meantime, an anomalous ascending branch occurs over the TP and Southeastern China (Figure 2B), along with the land surface cooling surrounding the TP with above-normal snowfall in early winter (Figure 2C).

\section{SSTAS ASSOCIATED WITH EARLY WINTER TP SNOWFALL}

Previous studies (Yuan et al., 2014; Jiang et al., 2019) implied that the anomalies of TP snow cover/depth and circulation in early winter can be ascribed to the heat forcing of low-latitude SSTAs. Figure 3 indicates that the significant positive SSTAs regressed against PC1 of early winter TP snowfall appear in the western Indian Ocean, while weak negative SSTAs emerge in the eastern Indian Ocean, constituting a positive Indian Ocean Dipole (IOD) pattern (Saji et al., 1999). Additionally, IOD can also preserve its footprints on the Tibetan Plateau via the Tibetan snow anomalies and influence the subsequent spring and summer climate even after its disappearance (Kripalani and Kulkarni, 1999). It is also found that another positive SSTA exists in the eastern equatorial Pacific, corresponding to an El Niño event (Figure 3). At the same time, wintertime air temperature over southeastern TP is related to convection anomaly over the western North Pacific, which is significantly affected by ENSO (Jiang et al., 2013). Is it possible that ENSO can affect snowfall over the TP?

\section{Statistical Analysis}

In general, IOD and ENSO peak in autumn and winter, respectively. Both of them have strong climate effects on the cold season of the Northern Hemisphere. The monthly Niño 3.4 and IOD indices used to measure the ENSO and IOD events are obtained from https://www.cpc.ncep.noaa.gov/data/indices. An intimate TCC exists between IOD and ENSO with a significant correlation coefficient of 0.47 during 1961-2018. As to the early winter snowfall over TP, the significant TCCs between PC1 and IOD and ENSO reach 0.50 and 0.31 , respectively. The partial TCC between PC1 and ENSO dramatically decreases to 0.10 after removing the IOD signal (Table 1). In contrast, the partial TCC between PC1 and IOD is 0.45 and remains remarkable while excluding the effect of ENSO. Therefore, IOD not only exerts a direct influence on the early winter snowfall over the TP but is also crucial for maintaining the linkage between PC1 and the ENSO event.

As a consequence, ENSO impacts on TP snowfall by depending on IOD; meanwhile, ENSO has contributed to the relationship between IOD and PC1. It is assumed that the early winter IOD and ENSO may affect the Tibetan Plateau snowfall both independently and concurrently. Yamagata et al. (2004) found that one-third of IOD events are connected with ENSO. Behera and Yamagata (2003) also verified that a significant fraction of IOD events were correlated with tropical Pacific variability, including ENSO. The influence of ENSO on Indian Ocean SSTs is characterized by taking the complex development of ENSO into account: the spatiotemporally varying impact of both canonical and non-canonical ENSO variability is estimated 

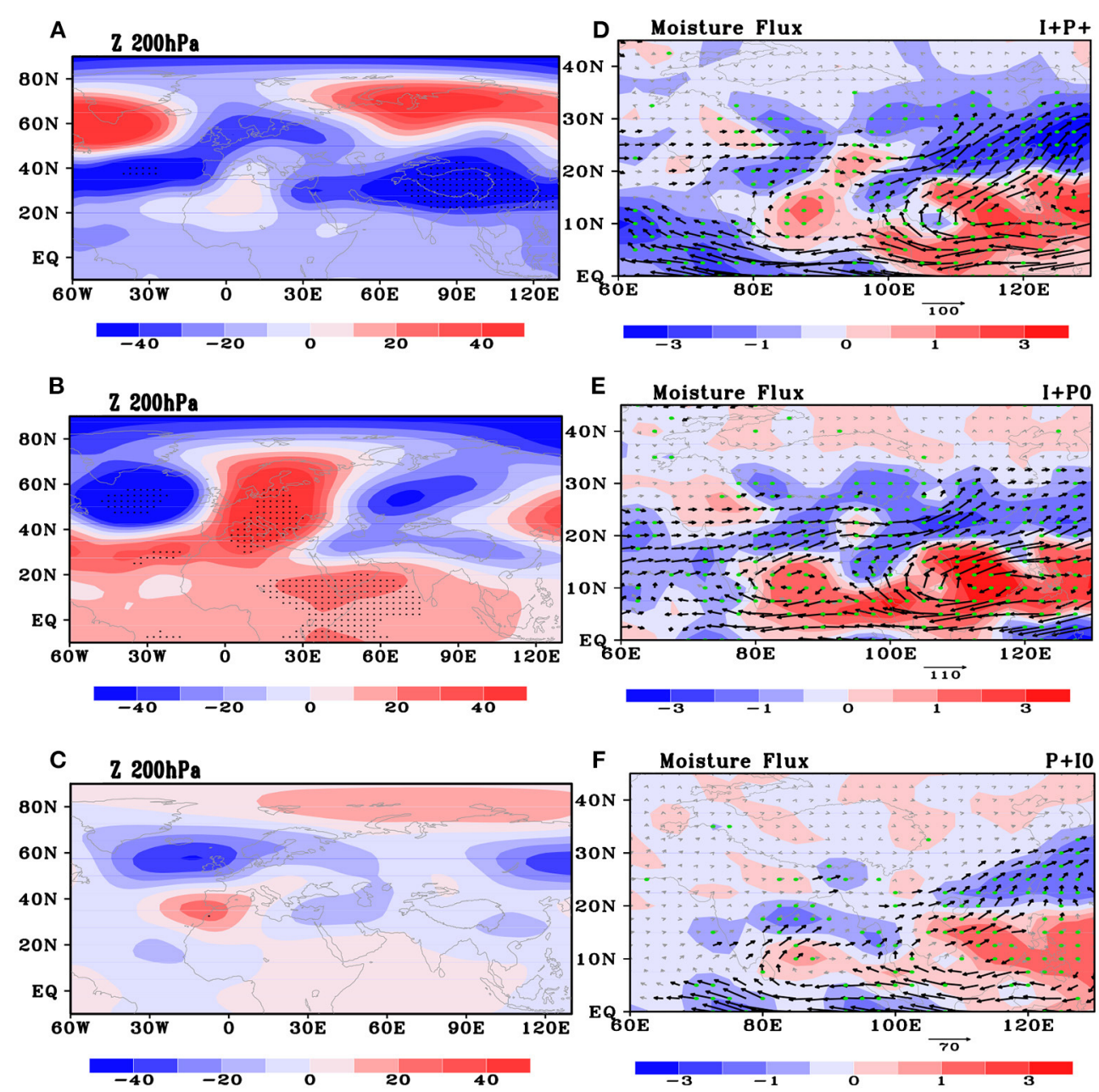

FIGURE 5 | The early winter circulation at positive IOD and ENSO combinations (A-C). For $200 \mathrm{hPa}$ geopotential height (gpm), (D-F). For moisture flux (kg m $\mathrm{m}^{-1} \mathrm{~s}^{-1}$ ). $(\mathbf{A}, \mathbf{D})$ refer to the positive IOD and El Niño combination case, (B,E) refer to the case of positive IOD and neutral ENSO, (C,F) refer to the case of positive El Niño and neutral IOD.

and filtered prior to the search for recurrent modes of SST variability in the Indian Ocean (Yamagata et al., 2004).

For further examination of the effects of IOD and ENSO, we divide the 58 years (during 1961-2018) into some categories based on the combinations of IOD and ENSO indices (Table 2). In this study, the strong IOD (ENSO) events are defined as the absolute value of the IOD (Nino 3.4) index above 0.7 standard deviation, whereas the other cases are in the neutral conditions. During 1961-2018, there are 6 (7) years with a strong positive (negative) IOD-ENSO combination, and 21 years with a normal IOD-ENSO combination (Tables 2, 3). Other years with either strong IOD or ENSO mainly represent the individual influence of strong IOD or ENSO.

As shown in Figure 4, the variation of early winter snowfall over the TP is quite different with IOD and ENSO combinations. The medium values of snowfall anomaly are above normal in the combinations of strong positive IOD events $\left(\mathrm{I}^{+}\right)$with positive $\left(\mathrm{P}^{+}\right)$or normal $\left(\mathrm{P}^{0}\right)$ ENSO events, while the snowfall is below normal in the combinations if the IOD presents the strong negative values $\left(\mathrm{I}^{-}\right)$. It is also noted that the medium PC1 of TP snowfall is positive when both IOD and ENSO are positive $\left(\mathrm{I}^{+} \mathrm{P}^{+}\right)$but lower than the combination with positive IOD and normal ENSO $\left(\mathrm{I}^{+} \mathrm{P}^{0}\right)$, indicating the positive ENSO won't further enhance the IOD's effect on producing more snowfall over the TP in early winter. Besides, the uncertainty of the PC1 of TP snowfall is large in the years with only a strong ENSO event $\left(\mathrm{P}^{+}\right)$, which is consistent with the insignificant partial TCC between ENSO and PC1 without an IOD event (Table 1). The early winter snowfall anomaly is quite close to zero with large uncertainty in the neutral IOD-ENSO combinations $\left(\mathrm{I}^{0} \mathrm{P}^{0}\right)$. Accordingly, the individual strong positive IOD or ENSO has a remote effect on motivating the early winter snowfall over the TP, but IOD plays a more important role than ENSO. It has also been verified in the study of the respective influences of IOD and ENSO on the TP snow cover in early winter (Yuan et al., 2009). 

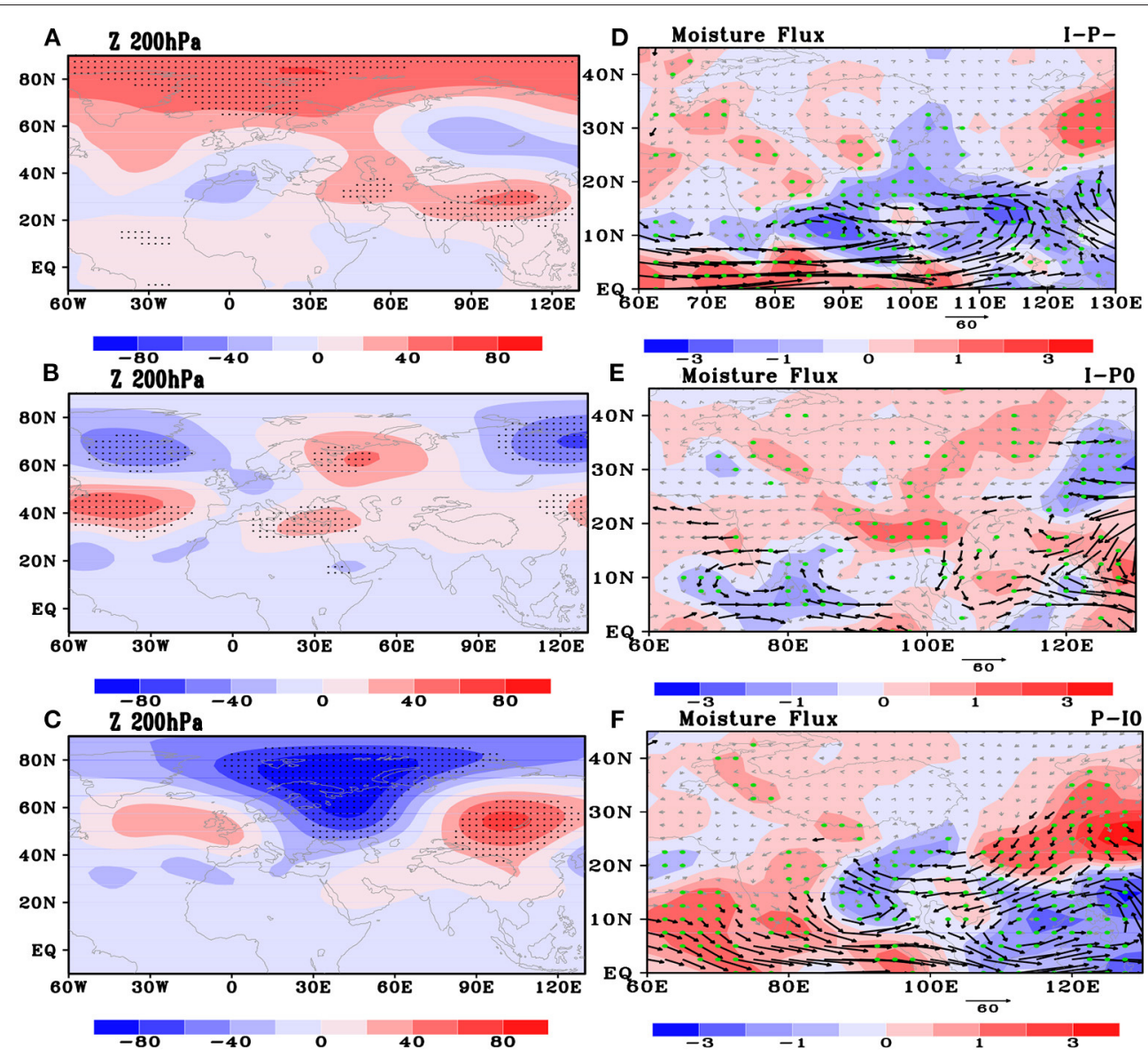

FIGURE 6 | As in Figure 5, but for the negative phases of IOD and ENSO.

\section{Composite Results}

We further investigate the combined effect of IOD and ENSO on TP snowfall in early winter by means of composite analysis for each category. In case of positive IOD and ENSO $\left(\mathrm{I}^{+} \mathrm{P}^{+}\right)$, the circulation anomaly is similar to the SEA-like pattern at 200-hPa level from western Europe to East Asia. Especially, the anomaly centers including Greenland, western Europe, and Northwest Africa just lie in the North pathway. That is consistent with the circulation facilitating the above-normal TP snowfall in early winter (Figures $\mathbf{2 A}, \mathbf{5 A}$ ). It is worth noting that the most remarkable negative anomaly occurs in the TP and its neighboring regions, which is in agreement with Figure 2A. These circulation anomalies are associated with warm and humid southwesterly anomalies to enter the TP and cause moisture convergence that dominates the whole TP region (Figure 5D). A strong ascending motion may imply an unstable atmospheric condition.

Figures 5B,E illustrate the circulation anomalies in positive IOD and neutral ENSO $\left(\mathrm{I}^{+} \mathrm{P}^{0}\right)$ case. A zonal wave train pattern across North Atlantic to Asia is observed at 200-hPa level. It is a Eurasian-like pattern and TP has been covered by negative anomaly, thus weaker than in Figures 5A,B. The maximum moisture convergence occurs in south of TP affected by air flow from the northwest Pacific and Arabian sea via the India Peninsula (Figure 5E), leading to above-normal snowfall in situ. It is dynamically consistent with the regression of geopotential height and wind anomalies against the PC1 of TP snowfall (Figure 2). It reflects that the positive IOD is conducive to motivating the atmospheric condition of TP snowfall in early winter. As demonstrated by Yamagata et al. (2004), positive IOD can cause convergence anomalies over the Mediterranean/Sahara region at the upper troposphere. With positive ENSO and neutral IOD $\left(\mathrm{P}^{+} \mathrm{I}^{0}\right)$ (Figures $\left.\mathbf{5} \mathbf{C}, \mathbf{F}\right)$, the circulation anomaly and water vapor transfer from the low-latitude region become more weaker than in $\mathrm{I}^{+} \mathrm{P}^{0}$ case.

Figure 6 gives the circulation anomalies based on the opposite combination including negative IOD and $\mathrm{ENSO}\left(\mathrm{I}^{-} \mathrm{P}^{-}\right)$, negative IOD and neutral ENSO $\left(\mathrm{I}^{-} \mathrm{P}^{0}\right)$, and negative ENSO and neutral IOD $\left(\mathrm{P}^{-} \mathrm{I}^{0}\right)$. It presents almost opposite characteristics to $\mathrm{I}^{+} \mathrm{P}^{+}$, $\mathrm{I}^{+} \mathrm{P}^{0}$, and $\mathrm{P}^{-} \mathrm{I}^{0}$ cases, which illustrates that IOD avails for the North pathway wave train development and negative anomalies on the TP.

In conclusion, the individual IOD can stimulate the SEA-like pattern from the Arabian sea via the TP to Northeast Asia; thus, the effect of the individual effect became weaker. Yuan et al. (2009) also revealed that the Eurasia waves can be generated by 
TABLE 4 | Schemes of the four CAM5 simulations.

\begin{tabular}{lll}
\hline Experiment name & Schemes & Integral times \\
\hline Control experiment (E0) & $\begin{array}{l}\text { CAM5 is forced by } \\
\text { global SST climatology } \\
\text { CAM5 is forced by SST } \\
\text { in both Indian and }\end{array}$ & $\begin{array}{l}\text { anomaly within both } \\
\text { tropical Indian and }\end{array}$ \\
Pacific Ocean (E1) & $\begin{array}{l}\text { Pacific Ocean } \\
\text { CAM5 is forced by SST } \\
\text { in Indian Ocean (E2) }\end{array}$ & $\begin{array}{l}\text { anomaly within the } \\
\text { tropical Indian Ocean } \\
\text { related to the } \\
\text { independent IOD with } \\
\text { no co-Occurrence of El }\end{array}$ \\
Niño \\
CAM5 is forced by SST \\
anomaly within the \\
tropical Pacific Ocean \\
related to the \\
independent El Niño \\
in Pacific Ocean (E3) \\
with no co-Occurrence \\
of IOD
\end{tabular}

the IOD-related convection anomalies over the western/central Indian Ocean. The anomalies of moisture supply and surface temperature over the TP are significant. All of which suggested the crucial influences of IOD on early winter TP snowfall, while the influences of ENSO is weaker.

\section{NUMERICAL EXPERIMENTS}

In order to further verify the effects of IOD and ENSO, one control experiment and three sensitivity experiments by CAM5 are implemented, respectively. The experiment schemes are listed in Table 4. As described in section Data, Method, and Model, the differences between the sensitivity and control runs show the influences of SSTA on TP early winter snowfall. In the first sensitivity experiment (E1), we prescribe the positive SST anomaly in the tropical western Indian and Pacific Ocean featured with positive IOD and ENSO phase (Figure 7A). The second experiment (E2) denotes an IOD-like pattern with the positive-negative anomaly seesaw in the western and eastern Indian Ocean (Figure 7B). The third experiment (E3) is referred to as El Niño condition in the tropical Pacific (Figure 7C). Based on these simulation experiments, we may able to further verify the individual or joint roles of IOD and ENSO on motivating the early winter snowfall-related atmospheric patterns over the TP and its surrounding regions.

Figure 8 shows the circulation response in the above three SST external forcing conditions. Compared with Figure 6, simulation results reproduce the circulation pattern, i.e., SEA-like pattern can be reproduced by forces of the positive IOD and ENSO $\left(\mathrm{I}^{+} \mathrm{P}^{+}\right)$(Figure 8A) or force of positive IOD $\left(\mathrm{I}^{+}\right)$(Figure 8B). Maybe due to model uncertainty, the $\mathrm{I}^{+}$corresponding pattern is a little bit weaker than $\mathrm{I}^{+} \mathrm{P}^{+}$.

Compared with the observations (Figure 5), the simulated anomaly phase and the location of anomaly centers are very similar to each other. Although the center of TP cannot be simulated exactly in the condition of positive IOD, it is still covered by the negative geopotential height anomalies south of the TP and the mid-low latitude, which is consistent with the above analysis. Besides, it is also presented that the simulated geopotential height anomalies for the $\mathrm{P}^{+} \mathrm{I}^{0}$ are quite weak over the TP region, which is consistent with the feature of Figure 6C. Therefore, individual positive ENSO has limited effect on motivating the SEA-like pattern and circulation anomalies around the TP region. Therefore, CAM5 simulation further confirmed that $\mathrm{I}^{+} \mathrm{P}^{+}$and $\mathrm{I}^{+} \mathrm{P}^{0}$ cases have remote effects on motivating the SEA-like pattern across Euro-Asia continent then cause geopotential height anomaly over the TP. Noteworthily, the anomaly of horizontal wind field have consistent in $\mathrm{I}^{+} \mathrm{P}^{+}$(Figure 9A) and $\mathrm{P}^{+}$cases (Figure 9C), the northwesterly prevailed over TP and an anticyclone occur in the southeastern $\mathrm{TP}$, which can hinder the warm moisture entering into the TP. On the contrary, in Figure $9 \mathrm{~B}$, the $\mathrm{I}^{+} \mathrm{P}^{0}$ force can produce an anticyclone at the southeastern TP, transporting more water vapor into the TP, providing the moisture condition for snowfall.

Besides, in Figures 10A-C, a $400-\mathrm{hPa}$ vertical velocity field shows an anomalous ascending motion in $\mathrm{I}^{+} \mathrm{P}^{+}$and $\mathrm{I}^{+} \mathrm{P}^{0}$ cases, which avails for more snowfall over the TP region. Therefore, the $\mathrm{I}^{+} \mathrm{P}^{+}$or $\mathrm{I}^{+} \mathrm{P}^{0}$ corresponding wind field and vertical motion in the middle troposphere can lead to heavy snowfall over the $\mathrm{TP}$ in early winter, while the function of $\mathrm{I}^{0} \mathrm{P}^{+}$is quite weak. Jiang et al. (2019) also revealed that anomalous convection over the western Indian Ocean related to the positive IOD could generate a wave train propagating northeastward and induce an anomalous cyclonic circulation over the central western of TP. The associated anomalous circulation transports extra moisture from the tropics to the central western TP, providing favorable conditions for more snowfall over the central western of TP.

\section{CONCLUSION AND DISCUSSION}

In this paper, we examine the interannual variability of TP snowfall in early winter and its underlying physical mechanisms based on observational and NCEP reanalysis data, and the mechanisms of respective and combined IOD and ENSO effects on TP snowfall are investigated using the CAM5 model.

The interannual oscillation indicated by the first EOF mode of TP snowfall in early winter shows good uniformity regionally, which is closely related to the SEA-like pattern from the North Atlantic to East Asian at mid and high latitudes. The TP region is characterized by negative geopotential height anomalies at $200 \mathrm{hPa}$, the vertical ascending motion at $400 \mathrm{hPa}$, and the negative temperature anomalies. Cyclonic circulation anomalies around the TP region intensified southwesterly moisture flow into the TP from the Arabians Sea and Bay of Bengal. All these circulation anomalies provide the favorable thermal and dynamical conditions for more snowfall over the TP.

Either the respective effect of IOD and ENSO, or their combined effect can motivate negative geopotential anomalies and cyclone water vapor flow in the surrounding area of TP. We note that the positive IOD could excite the obvious SEA-like 


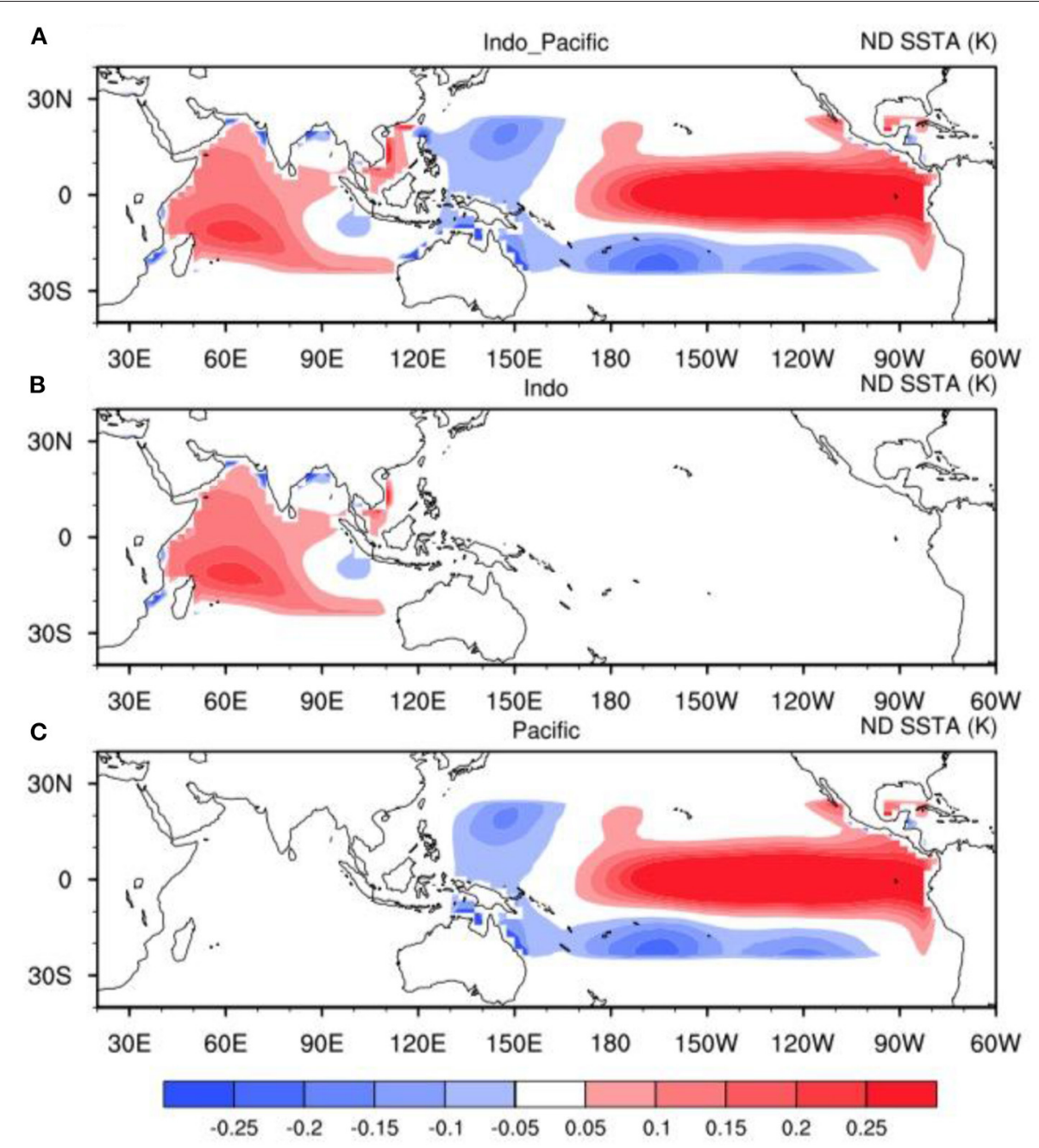

FIGURE 7 | The SST anomalous forcing scheme in model experiments. (A) SST forcing added in both western Indian ocean and tropical Pacific ocean, (B) SST forcing added only in the western Indian ocean, (C) SST forcing added only in the tropical Pacific ocean.

pattern, southerly moisture supply and vertical ascending motion over the TP. Therefore, IOD plays a leading role in producing uniform pattern of TP snowfall. While the respective effect of positive ENSO is weak and wouldn't enhance the IOD's effect on the early winter snowfall related atmospheric pattern over the TP and its surrounding region.

We have utilized the CAM5 model (the Community Atmosphere Model version 5) to reproduce the observed circulation anomalies related to the positive IOD and ENSO, which can explain their combined and respective effects on the TP snowfall in early winter. One control experiment and three sensitivity experiments by the CAM5 model were implemented to further verify the different roles of IOD and ENSO in motivating the SEA-like pattern and uniformed snowfall pattern over the TP. The differences in the influence of SSTA on the early winter snowfall over the TP are shown in the control and sensitivity runs. The simulated results further confirmed that the CAM5 model can depict the positive
IOD and the remote effect of ENSO in motivating the SEAlike circulation pattern, especially verifying that positive IOD can significantly enhance the moisture supply from the lowlatitude region and cause sufficient snowfall over the TP. As demonstrated by Jiang et al. (2019), convection anomalies over the western Indian Ocean associated with IOD could generate a barotropic Rossby wave that propagates northeastward along the South Asian wave guide. This Rossby wave induces an anomalous cyclonic circulation across the northern India, which transports more moisture to the TP from the tropics, providing a favorable condition for heavy snowfall and deepening of snow depth over the TP region. Sardeshmukh and Hoskins (1988), using a vorticity model, demonstrated that a divergence center over the tropical western Indian Ocean can directly generate the mid-latitude stationary Rossby waves with negative geopotential height anomalies north of India. More recently, Barlow et al. (2007) put an additional deep diabatic heating over the eastern Indian Ocean around the eastern pole of 


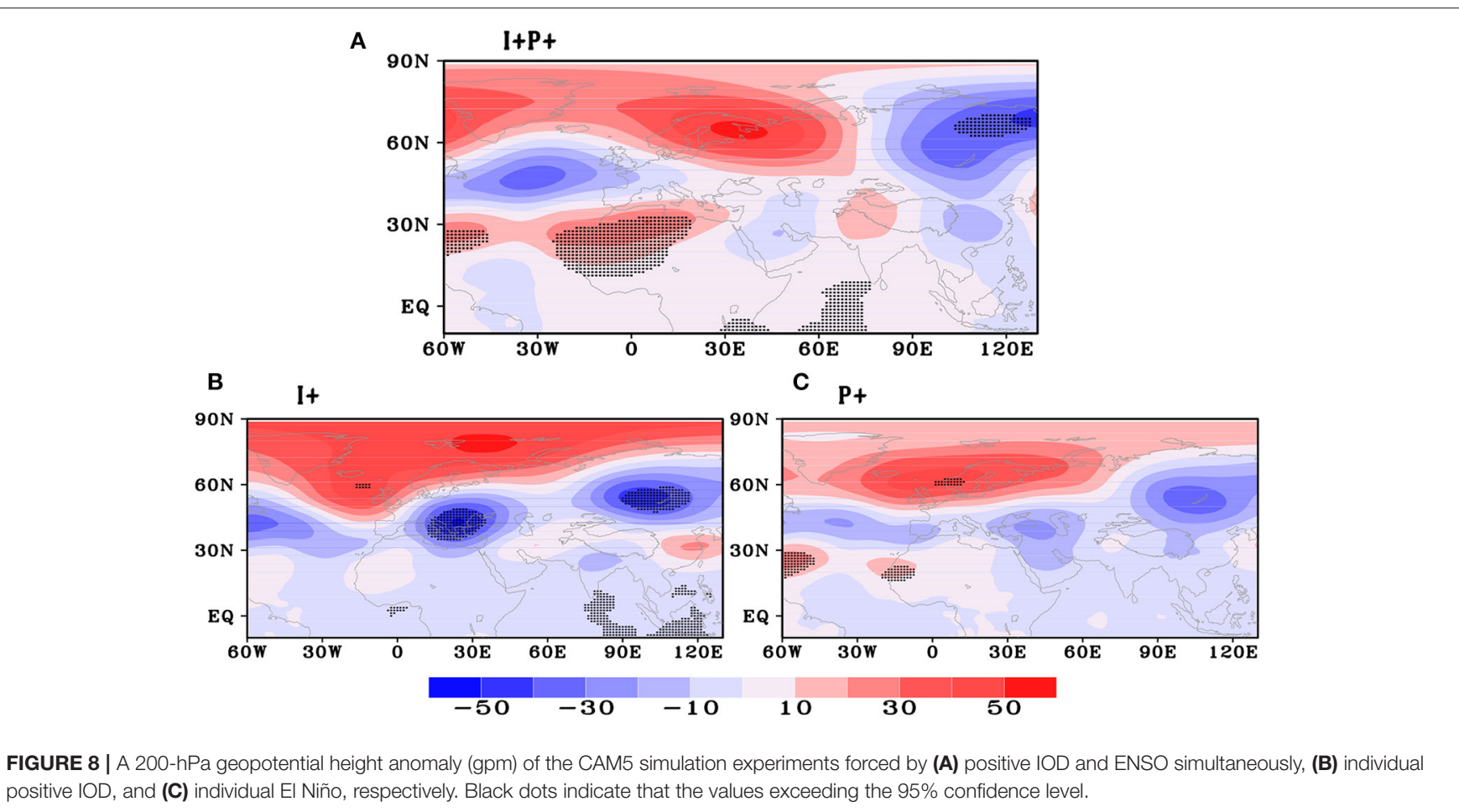

positive IOD, and (C) individual EI Niño, respectively. Black dots indicate that the values exceeding the 95\% confidence level.
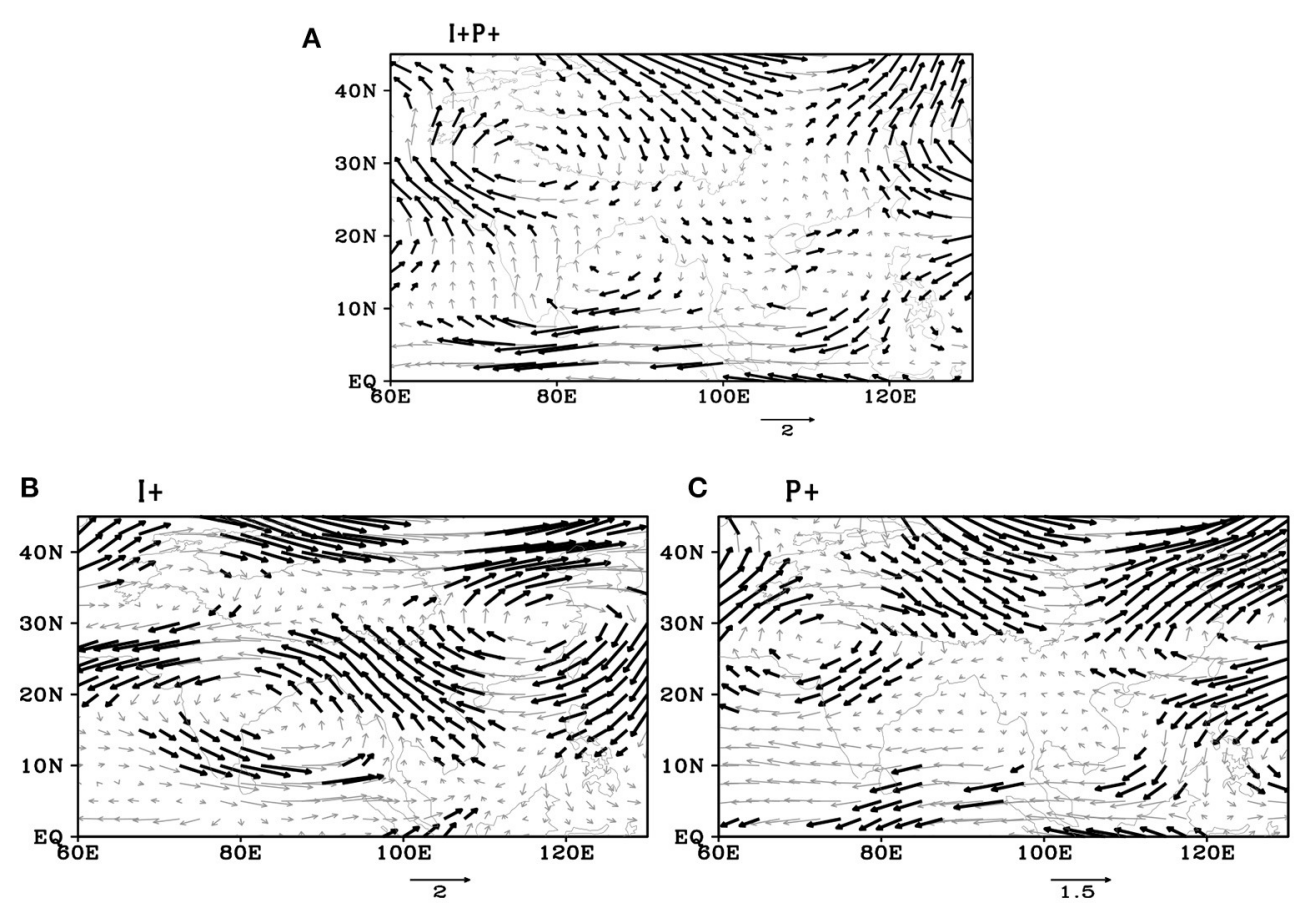

FIGURE 9 | As in Figure 8, but for 500-hPa horizontal wind anomaly field $\left(\mathrm{m} \mathrm{s}^{-1}\right)$. Bold vectors indicate that the values exceeding the $95 \%$ confidence level.

IOD in winter. Therefore, the Rossby waves along the wave guide in the early winter of pure IOD years may be caused by the IOD-related convection anomalies over the tropical Indian Ocean.
It is also noted that there is an uncertainty in the CAM5 model in climate simulation, especially for the middle- and high-latitude regions, which may lead to a certain bias in the simulated results presented in this study relative to the observation. 
A
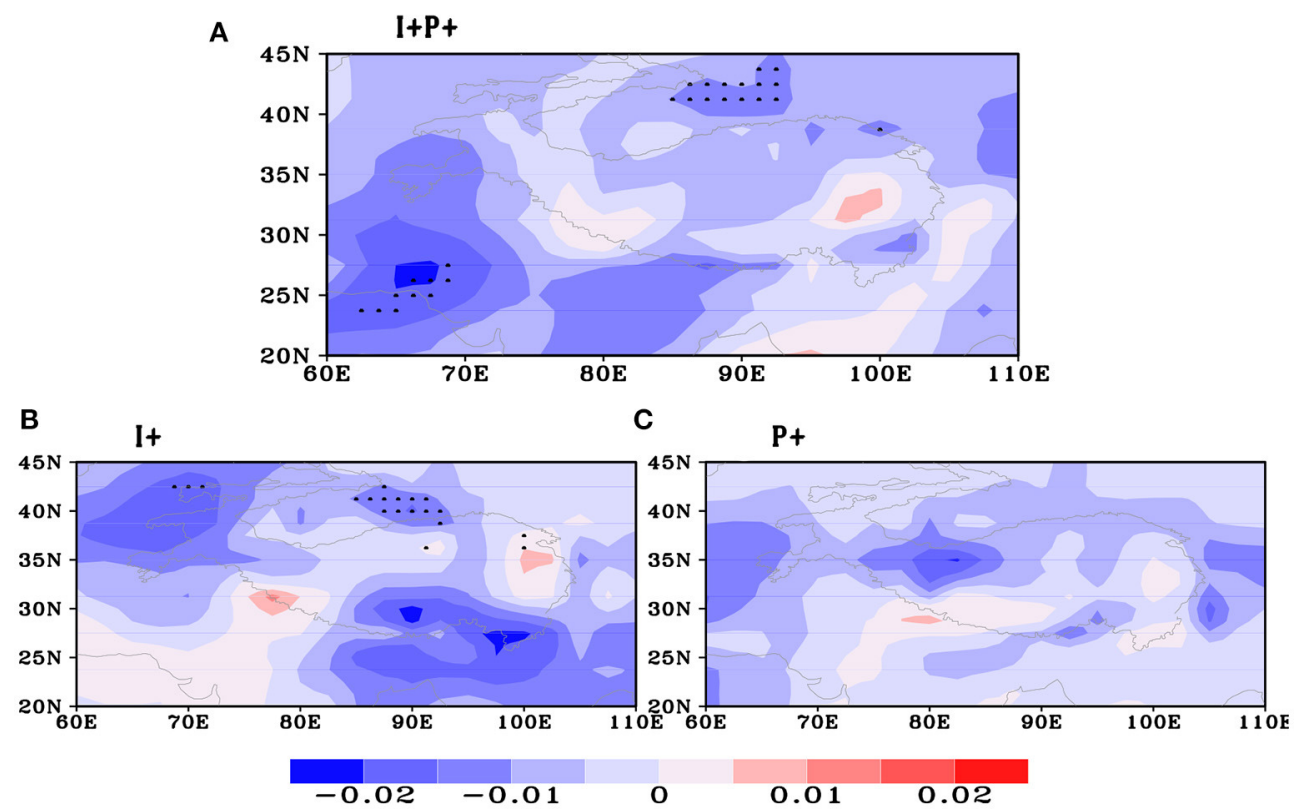

FIGURE 10 | As in Figure 8, but for the 400-hPa vertical velocity anomaly field $\left(\mathrm{m} \mathrm{s}^{-1}\right)$. Black dots indicate that the values exceeding the $95 \%$ confidence level.

\section{DATA AVAILABILITY STATEMENT}

The raw data supporting the conclusions of this article will be made available by the authors, without undue reservation.

\section{AUTHOR CONTRIBUTIONS}

ZG was responsible for writing the manuscript. BL was responsible for the numerical simulation. YG helped with the writing of the manuscript. XF and TW helped revise the manuscript. XW designed the thesis framework and helped

\section{REFERENCES}

Barlow, M., Hoell, A., and Colby, F. (2007). Examining the wintertime response to tropical convection over the Indian Ocean by modifying convective heating in a full atmospheric model. Geophys. Res. Lett. 34:L19702. doi: 10.1029/2007GL030043

Behera, S. K., and Yamagata, T. (2003). Influence of the Indian Ocean on the Southern Oscillation. J. Meteorol. Soc. Jpn. 81, 169-177. doi: $10.2151 /$ jmsj. 81.169

Danco, J. F., Deangelis, A. M., Raney, B. K., and Broccoli, A. J. (2016). Effects of a warming climate on daily snowfall events in the Northern Hemisphere. J. Clim. 29, 6295-6318. doi: 10.1175/JCLI-D-15-0687.1

Dong, B., and Valdes, P. J. (1998). Simulations of the Last Glacial Maximum climates using a general circulation model: prescribed versus computed sea surface temperatures. Clim. Dyn. 14, 571-591. doi: 10.1007/s003820050242

Frei, A., Tedesco, M., Lee, S., Foste, J., Hall, D. K., Kelly, R., et al. (2012). A review of global satellite-derived snow products. Adv. Space Res. 50, 1007-1029. doi: 10.1016/j.asr.2011.12.021

Ge, J. W., Jia, X. J., and Lin, H. (2016). The interdecadal change of the leading mode of the winter precipitation over China. Clim. Dyn. 47, 2397-2411. doi: $10.1007 / \mathrm{s} 00382-015-2970-\mathrm{x}$ with the writing of the manuscript. GF helped the writing of the manuscript.

\section{FUNDING}

This work was supported by the National Key Research and Development Program of China (2018YFC1507702) and the National Natural Science Foundation of China Project (42065003, 42075057, and 41875100), Qinghai Science and Technology Department Project (2021-ZJ-757), and Opening Fund of Key Laboratory of Land Surface Process and Climate Change in Cold and Arid Regions, CAS (LPCC2019009).

Gong, Z. Q., Feng, G., Dogar, M. M., and Huang, G. (2017). The possible physical mechanism for the EAP-SR co-action. Clim. Dyn. 132, 1156-1163. doi: 10.1007/s00382-017-3967-4

Gong, Z. Q., Feng, G. L., Ren, F. M., and Li, J. (2014). A regional extreme low temperature event and its main atmospheric contributing factors. Theor. Apply Climatol. 117, 195-206. doi: 10.1007/s00704-013-0997-7

Groisman, P. Y., Knight, R. W., Karl, T. R., and Karl, T. R. (2001). Heavy precipitation and high streamflow in the contiguous United States: trends in the twentieth century. Bull. Amer. Meteorol. Soc. 82, 219-246. doi: 10.1175/1520-0477(2001)082<0219:HPAHSI >2.3.CO;2

Huang, W. J., and Cai, W. J. (2017). Eutrophication-induced acidification of coastal waters in the northern Gulf of Mexico: insights into origin and processes from a coupled physical-biogeochemical model. Geohys. Res Lett. 12:L19801. doi: 10.1002/2016GL071881

Jia, X. J., and Lin, H. (2011). Influence of forced large-scale atmo-spheric patterns on surface air temperature in China. Mon. Wea. Rev. 139, 830-852. doi: 10.1175/2010MWR3348.1

Jiang, X., Li, Y., Yang, S., Ke, Z., Li, J., and Hu, H. (2013). Dominant modes of wintertime upper-tropospheric temperature variations over Asia and links to surface climate. J. Clim. 26, 9043-9060. doi: 10.1175/JCLI-D-1200774.1 
Jiang, X. W., Zhang, T. T., Tam, C. Y., Chen, J., Lau, N. C., Yang, S., et al. (2019). Impacts of ENSO and IOD on snow depth over the Tibetan Plateau: roles of convections over the western North Pacific and Indian Ocean. J. Geophys Res. Atmos. 124, 11961-11975. doi: 10.1029/2019JD031384

Kalney, E., Kanamitsu, M., Kistler, R., Collins, W., Deaven, D., Gandin, L., et al. (1996). The NCEP/NCAR 40-year reanalysis project. Bull. Am. Meteorol. Soc. 74, 789-799. doi: 10.1175/1520-0477(1996)077<0437:TNYRP > 2.0.CO;2

Khairoutdinov, M. F., and Randall, D. A. (2001). A cloud resolving model as a cloud parameterization in the NCAR Community Climate System Model: preliminary results. Geophys. Res. Lett, 28, 3617-3620. doi: 10.1029/2001GL013552

Kripalani, R. H., and Kulkarni, A. (1999). Climatology and variability of historical Soviet snow depth data: Some new perspectives in snow-Indian monsoon teleconnections. Clim. Dyn. 15, 475-489. doi: 10.1007/s003820050294

Lettenmaier, D., and Gan, T. (1990). Hydrologic sensitivities of the SacramentoSan Joaquin River basin, California, to global warming. Water Resour. Res. 26, 69-86. doi: 10.1029/WR026i001p00069

Li, J. P. (2016). "Impacts of annular modes on extreme climate events over the East Asian monsoon region," in Dynamics and Predictability of Large-scale HighImpact Weather and Climate Events (Beijing: Cambridge University Press), 343-353. doi: 10.1017/CBO9781107775541.028

Li, J. P., Zheng, F., Sun, C., Feng, J., and Wang, J. (2019). Pathways of influence of the Northern Hemisphere mid-high latitudes on East Asian climate: a review. Adv. Atmos. Sci. 36, 902-921. doi: 10.1007/s00376-019-8236-5

Meehl, G. A. (1997). The south Asian monsoon and the tropospheric biennial oscillation. J. Clim. 10, 1921-1943. doi: 10.1175/1520-0442(1997)010<1921:TSAMAT>2.0.CO;2

Saji, N. H., Goswami, B. N., Vinayachandran, P. N., and Yamagata, T. (1999). A dipole mode in the tropical Indian Ocean. Nature 401, 360-363. doi: $10.1038 / 43854$

Sardeshmukh, P., and Hoskins, B. (1988). The generation of global rotational flow by steady idealized tropical divergence. J. Atmos. Sci. 45, 1228-1251. doi: 10.1175/1520-0469(1988)045<1228:TGOGRF > 2.0.CO;2

Schieman, R. D., Luethi, P. L., and Schaer, C. (2009). Seasonality and interannual variability of the westerly jet in the Tibetan Plateau region. J. Clim. 22, 2940-2957. doi: 10.1175/2008JCLI2625.1

Shaman, J., and Tziperman, E. (2005). The effect of ENSO on Tibetan Plateau snow depth: a stationary wave teleconnection mechanism and implications for the South Asian monsoons. J. Clim. 18, 2067-2078. doi: 10.1175/JCLI3391.1

Simmons, A. J., and Burridge, D. M. (1981). An energy and angular-momentum conserving vertical finite-difference scheme and hybrid vertical coordinates. Mon. Wea. Rev. 109, 758-766. doi: 10.1175/1520-0493(1981)109<0758:AEAAMC>2.0.CO;2

Sun, J. H., and Wang, W. Y. (2010). Spatial-temporal features of intense snowfall events in China and their possible change. J. Geophys. Res. 115, 136-149. doi: 10.1029/2009JD013541

Takaya, K., and Nakamura, H. (2001). A formulation of a phase-independent wave-activity flux for stationary and migratory quasi geostrophic eddies on a zonally varying basic flow. J. Atmos. Sci. 58, 608-627. doi: 10.1175/1520-0469(2001)058<0608:AFOAPI>2.0.CO;2

Wallace, J. M., and Gutzler, D. S. (1981). Teleconnections in the geopotential height field during the Northern Hemisphere winter. Mon. Wea. Rev. 109, 784-812. doi: 10.1175/1520-0493(1981)109<0784:TITGHF > 2.0.CO;2

Wang, B., Wu, R. G., and Fu, X. H. (2000). Pacific-East Asian teleconnection: how does ENSO affect Asian climate? J. Clim. 13, 1517-1536. doi: 10.1175/1520-0442(2000)013<1517:PEATHD > 2.0.CO;2

Wang, L., and Chen, W. (2010). How well do existing indices mea-sure the strength of the East Asian winter monsoon? Adv. Atmos. Sci. 27, 855-870. doi: 10.1007/s00376-009-9094-3

Wang, L., and Chen, W. (2014). The East Asian winter monsoon: reamplification in the mid-2000s. Chin. Sci. Bull. 59, 430-436. doi: 10.1007/s11434-013-0029-0

Wang, L., and Feng, J. (2011). Two major modes of the wintertime precipitation over China. Chin. J. Atmos. Sci. 35, 1105-1116. (in Chinese). doi: 10.3878/j.issn.1006-9895.2011.06.10
Wang, Y., and Xu, X. (2018). Impact of ENSO on the thermal condition over the Tibetan Plateau. J. Meteorol. Soc. Jpn. 96, 269-281. doi: 10.2151/jmsj.2018-032

Webster, P. J. (1998). Monsoons: processes, predictability, and the prospects for prediction. J. Geophys. Res. 103, 14451-14510. doi: 10.1029/97JC02719

Wu, Z., Li, J., Jiang, Z., and Ma, T. (2012). Modulation of the Tibetan Plateau snow cover on the ENSO teleconnections: from the East Asian summer monsoon perspective. J. Clim. 25, 2481-2489. doi: 10.1175/JCLI-D-11-00135.1

Wu, Z. W., Li, J. P., Jiang, Z. H., and He, J. (2011). Predictable climate dynamics of abnormal East Asian winter monsoon: once-in-a-century snowstorms in 2007/2008 winter. Clim. Dyn. 37, 1661-1669. doi: 10.1007/s00382-010-0938-4

$\mathrm{Xu}, \mathrm{H} ., \mathrm{Li}, \mathrm{J}$. , Feng, J., and Mao, J. (2012). The asymmetric relationship between the winter $\mathrm{NAO}$ and the precipitation in Southwest China. Acta Meteorol. Sin. 70, 1276-1291. doi: 10.11676/qxxb2012.107 (in Chinese).

Yamagata, T., Behera, S. K., Luo, J. J., Masson, S., Jury, M. R., and Rao, S. A. (2004). Coupled Ocean-Atmosphere variability in the tropical Indian Ocean. Geophy. Monogr. 147, 189-211. doi: 10.1029/147GM12

Yang, S. (1996). ENSO-snow-monsoon associations and seasonal interannual predictions. Clim. Dyn. 16, 125-134. doi: 10.1002/(SICI)1097-0088(199602)16:2<125::AID-JOC999>3.0.CO;2-V

Yuan, C. X., Tozuka, T., Luo, J. J., and Yamagat, T. (2014). Predictability of the subtropical dipole modes in a coupled ocean-atmosphere model. Climate Dyn. 42, 1291-1308. doi: 10.1007/s00382-013-1704-1

Yuan, C. X., Tozuka. T., Miyasaka, T., and Yamagata, T. (2009). Respective influences of IOD and ENSO on the Tibetan snow cover in early winter. Climate Dyn. 33, 509-520. doi: 10.1007/s00382-008-0495-2

Zhang, Y., Zhou, W., Chow, E. C., and Leung, M. Y. T. (2019). Delayed impacts of the IOD: cross-seasonal relationships between the IOD, Tibetan Plateau snow, and summer precipitation over the Yangtze-Huaihe River region. Clim. Dyn. 53, 4077-4093. doi: 10.1007/s00382-019-04774-5

Zhou, B., Gu, L., Ding, Y., Shao, L., Wu, Z., Yang, X., et al. (2011). The great 2008 Chinese ice storm: its socioeconomic-ecological impact and sustainability lessons learned. Bull. Amer. Meteorol. Soc. 92, 47-60. doi: 10.1175/2010BAMS2857.1

Zhou, B., Wang, Z., and Shi, Y. (2017). Possible role of hadley circulation strengthening in interdecadal intensification of snowfalls over northeastern China under climate change. J. Geophys. Res. 122:265-283. doi: 10.1002/2017JD027574

Zhou, L., and Wu, R. (2010). Respective impacts of the East Asian winter monsoon and ENSO on winter rainfall in China. J. Geophys. Res. 115:D02107. doi: 10.1029/2009JD012502

Zhou, W., Chan, J. C. L., Chen, W., Ling, J., Pinto, J. G., and Shao, Y. (2009). Synoptic-scale controls of persistent low temperature and icy weather over Southern China in January 2008. Mon. Wea. Rev. 137, 3978-3991. doi: 10.1175/2009MWR2952.1

Conflict of Interest: The authors declare that the research was conducted in the absence of any commercial or financial relationships that could be construed as a potential conflict of interest.

Publisher's Note: All claims expressed in this article are solely those of the authors and do not necessarily represent those of their affiliated organizations, or those of the publisher, the editors and the reviewers. Any product that may be evaluated in this article, or claim that may be made by its manufacturer, is not guaranteed or endorsed by the publisher.

Copyright (c) 2021 Shen, Gong, Liu, Guo, Feng, Wen, Wang and Feng. This is an open-access article distributed under the terms of the Creative Commons Attribution License (CC BY). The use, distribution or reproduction in other forums is permitted, provided the original author(s) and the copyright owner(s) are credited and that the original publication in this journal is cited, in accordance with accepted academic practice. No use, distribution or reproduction is permitted which does not comply with these terms. 